Case Report

\title{
Glucocorticoid-Responsive Cold Agglutinin Disease in a Patient with Rheumatoid Arthritis
}

\author{
Kyoko Honne, ${ }^{1}$ Takao Nagashima, ${ }^{1}$ Masahiro Iwamoto, ${ }^{1}$ \\ Toyomi Kamesaki, ${ }^{2}$ and Seiji Minota ${ }^{1}$ \\ ${ }^{1}$ Division of Rheumatology and Clinical Immunology, Department of Medicine, Jichi Medical University, Yakushiji 3311-1, \\ Shimotsuke, Tochigi 329-0498, Japan \\ ${ }^{2}$ Center for Community Medicine, Jichi Medical University, Yakushiji 3311-1, Shimotsuke, Tochigi 329-0498, Japan
}

Correspondence should be addressed to Takao Nagashima; naga4ma@jichi.ac.jp

Received 4 April 2015; Accepted 27 July 2015

Academic Editor: Mario Salazar-Paramo

Copyright (C) 2015 Kyoko Honne et al. This is an open access article distributed under the Creative Commons Attribution License, which permits unrestricted use, distribution, and reproduction in any medium, provided the original work is properly cited.

A 57-year-old man with rheumatoid arthritis developed severe anemia during treatment with adalimumab plus methotrexate. Cold agglutinin disease was diagnosed because haptoglobin was undetectable, cold agglutinin was positive $(1: 2048)$, and the direct Coombs test was positive (only to complement). Although the cold agglutinin titer was normalized (1:64) after treatment with prednisolone $(0.7 \mathrm{mg} / \mathrm{kg} / \mathrm{day}$ for two weeks), the patient's hemoglobin did not increase above $8 \mathrm{~g} / \mathrm{dL}$. When cold agglutinins were reexamined using red blood cells suspended in bovine serum albumin, the titer was still positive at 1:1024. Furthermore, the cold agglutinin had a wide thermal amplitude, since the titer was $1: 16$ at $30^{\circ} \mathrm{C}$ and $1: 1$ at $37^{\circ} \mathrm{C}$. This suggested that the cold agglutinin would show pathogenicity even at body temperature. After the dose of prednisolone was increased to $1 \mathrm{mg} / \mathrm{kg} / \mathrm{day}$, the patient's hemoglobin rapidly returned to the normal range. The thermal amplitude test using red blood cells suspended in bovine serum albumin is more sensitive than the standard test for detecting pathogenic cold agglutinins.

\section{Introduction}

Cold agglutinin disease (CAD) is an immune-mediated hemolytic anemia caused by IgM autoantibodies (cold agglutinins) that exhibit maximum reactivity with human red blood cells (RBC) at low temperatures of $0-4^{\circ} \mathrm{C}$ [1]. CAD accounts for 8 to $25 \%$ of autoimmune hemolytic anemia [1$3]$. It is classified as primary (idiopathic) or secondary, and secondary CAD has two main causes that are malignancy or infections $[1,3]$.

CAD is rarely associated with connective tissue diseases $[2,4]$ and there have been few case reports of this disease in patients with rheumatoid arthritis (RA) [5-7]. Although $\mathrm{CAD}$ is an autoimmune disorder, glucocorticoid treatment is generally ineffective. This provides a sharp contrast with warm autoimmune hemolytic anemia, which generally shows a good response to glucocorticoids $[1,4]$. Here we report a patient with RA who developed acute-onset CAD and showed a good response to glucocorticoid treatment.

\section{Case Report}

A 57-year-old man had an 8-year history of RA and had been treated with methotrexate for 6 years. Biweekly injection of adalimumab had been started 6 months earlier to suppress disease activity. He showed a good response to adalimumab and achieved clinical remission. After seven doses, adalimumab and methotrexate were both suspended due to upper respiratory tract infection. One month later, he suddenly developed severe anemia that was unresponsive to blood transfusion (Figure 1). He was then referred to our hospital for assessment.

On admission, laboratory tests revealed a white blood cell count of $11,300 / \mu \mathrm{L}, \mathrm{RBC}$ count of $191 \times 10^{4} / \mu \mathrm{L}$, hemoglobin of $6.2 \mathrm{~g} / \mathrm{dL}$, mean corpuscular volume of $95 \mathrm{fL}$, platelet count of $48.2 \times 10^{4} / \mu \mathrm{L}$, and reticulocyte count of $18.3 \%$. There were spherocytes in the peripheral blood smear, but he had no family history of hereditary spherocytosis. Total bilirubin was $2.3 \mathrm{mg} / \mathrm{dL}$ (normal $\leq 1.5$ ), direct bilirubin 


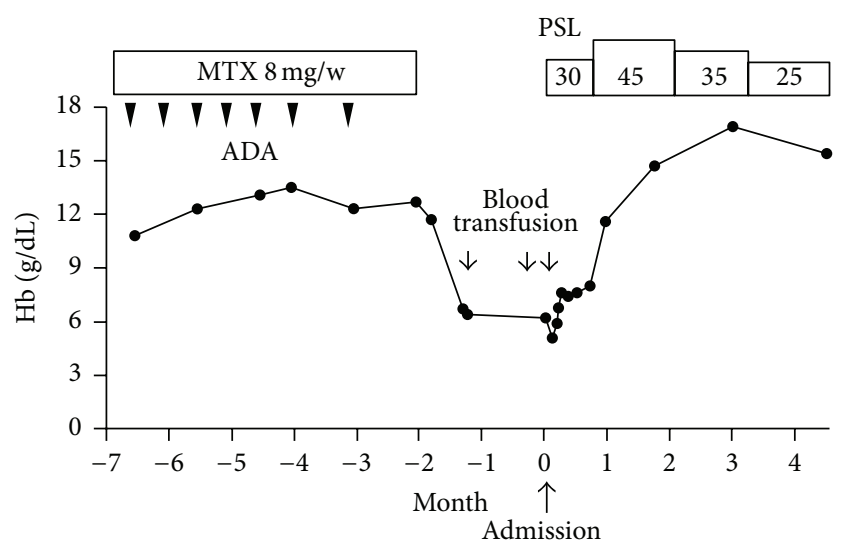

Figure 1: Clinical course of the patient and hemoglobin levels. ADA: adalimumab; Hb: hemoglobin; MTX: methotrexate; PSL: prednisolone (mg/day).

was $0.1 \mathrm{mg} / \mathrm{dL}$, lactate dehydrogenase was $351 \mathrm{U} / \mathrm{L}$ (normal $\leq 216$ ), and C-reactive protein was $7.6 \mathrm{mg} / \mathrm{dL}$. Rheumatoid factor and anticyclic citrullinated peptide antibody were positive, but antinuclear antibody and anti-double-stranded DNA antibody were negative. Complement components C3 and C4 were $90 \mathrm{mg} / \mathrm{dL}$ (normal: 86-160) and $12 \mathrm{mg} / \mathrm{dL}$ (normal: 17-45), respectively. Serum immunoelectrophoresis revealed no monoclonal proteins. Haptoglobin was below the detection limit. The direct Coombs test was negative for IgG but was positive for complement. Cold agglutinin was positive at 1 : 2048 (normal < $1: 128$ ). Serology for Mycoplasma pneumoniae was negative, and examination of anti-EpsteinBarr virus antibodies suggested a postinfectious state. There had been no episodes of hemoglobinuria, acrocyanosis after exposure to cold, or Raynaud's phenomenon. Because the patient's hemoglobin decreased further to $4.5 \mathrm{~g} / \mathrm{dL}$, two units of RBC were transfused and treatment was started with prednisolone (PSL) at $30 \mathrm{mg} / \mathrm{day}(0.7 \mathrm{mg} / \mathrm{kg})$ under the diagnosis of CAD. Although cold agglutinin became negative $(1: 64)$ after treatment with PSL for two weeks, his hemoglobin did not recover above $8 \mathrm{~g} / \mathrm{dL}$. Haptoglobin was still below the detection limit and complement component C3 decreased further to $67 \mathrm{mg} / \mathrm{dL}$. We reexamined cold agglutinins using RBC suspended in bovine serum albumin, instead of RBC suspended in saline. The test revealed that the cold agglutinin titer was $1: 1024$ at $4^{\circ} \mathrm{C}, 1: 16$ at $30^{\circ} \mathrm{C}$, and $1: 1$ at $37^{\circ} \mathrm{C}$. This suggested that cold agglutinin was still present and that hemolysis was continuing because the agglutinin was reactive at temperatures above $30^{\circ} \mathrm{C}$.

The dose of PSL was increased from $30 \mathrm{mg} /$ day to $45 \mathrm{mg} /$ day $(1 \mathrm{mg} / \mathrm{kg})$ and the patient's hemoglobin increased rapidly to $14.7 \mathrm{~g} / \mathrm{dL}$ after one month, while complement levels returned to the normal range after three months. Readministration of methotrexate with tapering of PSL did not lead to the recurrence of hemolysis. A lymphoproliferative disorder has not emerged after more than four years.

\section{Discussion}

In this patient, CAD developed during the course of RA and showed a good response to glucocorticoid therapy.
Because upper respiratory tract infection preceded the sudden decrease of hemoglobin, an unknown viral infection was the most likely cause of CAD. However, acute-onset CAD associated with infection is usually self-limiting and resolves within several weeks $[3,8,9]$, while hemolysis continued for more than two months in our patient, which is a relatively long duration. Since CAD is an immune-mediated disorder, an association with RA is possible $[4,6]$. Adalimumab could also be considered as the cause, because etanercept (another antitumor necrosis factor agent) has been reported to induce CAD [5].

Detection of cold agglutinins by using RBC suspended in bovine serum albumin is reported to be more sensitive than by using RBC suspended in saline $[10,11]$. Reduction of the zeta potential has been proposed as one of the mechanisms by which bovine serum albumin increases sensitivity for cold agglutinins [12]. In the present patient, although cold agglutinin became negative in the standard test after treatment with PSL for two weeks, the titer was still high $(1: 1024)$ when measured using bovine serum albumin. Furthermore, it became evident that the thermal amplitude (the highest temperature at which the autoantibody binds to $\mathrm{RBC}$ ) was wide and agglutination occurred even at $30^{\circ} \mathrm{C}$ to $37^{\circ} \mathrm{C}$. The pathogenicity of a cold agglutinin depends on its thermal amplitude rather than the agglutinin titer $[1,9]$. If a cold agglutinin is reactive at temperatures above $30^{\circ} \mathrm{C}$, it can cause hemolysis in vivo.

Primary chronic CAD is generally refractory to pharmacotherapy, including glucocorticoids [13, 14], although some cases of glucocorticoid-responsive CAD have been reported $[13,15,16]$. When CAD responds to glucocorticoid therapy, the cold agglutinin titer tends to be relatively low and the agglutinin has a wide thermal range [13]. In the present patient, the cold agglutinin also had such features. Patients with these findings are sometimes classified as having "low-titer" CAD. However, the definition of "low-titer" is not completely clear, although a titer of less than 1000 was considered to be low in the original report [13]. Patients with acute hemolysis and polyclonal cold agglutinins may also respond to glucocorticoid therapy and this is a feature of infection-related CAD $[3,8]$. In fact, efficacy of glucocorticoids has been reported in some patients who developed CAD associated with Mycoplasma infection [14, 17, 18].

We reviewed nine patients who had CAD associated with connective tissue diseases and were reported in the English literature (Table 1) [5, 6, 19-24]. The cold agglutinin titer was less than 1000 in six of these nine patients. Most of them had severe anemia. Various treatments were reported and all of the patients except one responded. The treatments included hydroxychloroquine, low-dose/high-dose PSL with or without immunosuppressants, and rituximab. No treatment was given to one patient with polymyalgia rheumatica, who was also the only patient with a monoclonal cold agglutinin. Therefore, CAD associated with connective tissue diseases may respond to glucocorticoid therapy if a monoclonal cold agglutinin is not detected. Primary chronic CAD is usually resistant to glucocorticoid therapy and monoclonal IgM is found in $90 \%$ of these patients [3]. 
TABLE 1: Characteristics of the patients who had CAD associated with connective tissue diseases.

\begin{tabular}{|c|c|c|c|c|c|c|c|c|}
\hline Case number & Diagnosis & Age, sex & $\begin{array}{c}\text { Raynaud's } \\
\text { phenomenon or } \\
\text { acrocyanosis }\end{array}$ & Splenomegaly & CA titer & $\begin{array}{c}\text { Monoclonal } \\
\text { IgM }\end{array}$ & $\mathrm{Hb}(\mathrm{g} / \mathrm{dL})$ & Treatment \\
\hline 1 & SSc & $60, \mathrm{~F}$ & Yes & Yes & $1: 256^{\dagger}$ & No & 6.1 & Pulse + mPSL (60 mg) \\
\hline 2 & SS & $78, \mathrm{~F}$ & Yes & n.d. & $1: 64$ & n.d. & 5.0 & $\begin{array}{l}\text { PSL (10 mg), dopamine, } \\
\text { pyridoxal, } \mathrm{PGE}_{1} \text {, and } \\
\text { systemic warming }\end{array}$ \\
\hline 3 & SLE & $55, \mathrm{~F}$ & n.d. & n.d. & $1: 512$ & n.d. & 7.9 & $\begin{array}{l}\text { Pulse with PSL ( } 30 \mathrm{mg}) \\
\text { relapse: PSL ( } 40 \mathrm{mg}), \mathrm{DFPP}, \\
\text { CyA, and RTX }\end{array}$ \\
\hline 4 & SLE & $27, \mathrm{~F}$ & No & No & $1: 7000$ & No & 6.7 & $\begin{array}{l}\text { Prednisone }(40 \mathrm{mg}) \text { and } \\
\text { plaquenil }\end{array}$ \\
\hline 5 & SLE & $34, \mathrm{~F}$ & No & Yes & $1: 4096$ & n.d. & 6.0 & PSL $(60 \mathrm{mg})$ \\
\hline 6 & RA & $52, \mathrm{~F}$ & n.d. & n.d. & $1: 512$ & No & 9.1 & $\begin{array}{l}\text { PSL }(1 \mathrm{mg} / \mathrm{kg}), \text { CyA, and } \\
\text { RTX }\end{array}$ \\
\hline 7 & RA & $89, \mathrm{~F}$ & Yes & No & $1: 320$ & No & $31 \%^{*}$ & Hydroxychloroquine \\
\hline 8 & PMR & $60, \mathrm{M}$ & Yes & n.d. & $1: 256^{\dagger}$ & Yes & 8.0 & Avoiding cold \\
\hline Present case & RA & $57, \mathrm{M}$ & No & No & $1: 2048$ & No & 6.2 & PSL (1 mg/kg) \\
\hline
\end{tabular}

CA, cold agglutinin; CAD, cold agglutinin disease; CyA, cyclosporin; DFPP, double-filtration plasmapheresis; Hb, hemoglobin; Ht, hematocrit; mPSL, methylprednisolone; n.d., not described; $\mathrm{PGE}_{1}$, prostaglandin $\mathrm{E}_{1}$; PMR, polymyalgia rheumatica; PSL, prednisolone; RA, rheumatoid arthritis; RTX, rituximab; SLE, systemic lupus erythematosus; SS, Sjögren’s syndrome; SSc, systemic sclerosis. ${ }^{\dagger}$ The titer was measured at room temperature. ${ }^{\ddagger}$ Hematocrit.

In conclusion, high-dose glucocorticoid therapy was effective for acute-onset CAD in a patient with RA. The thermal amplitude test using RBC suspended in bovine serum albumin is more sensitive than the standard test for detecting pathogenic cold agglutinins.

\section{Conflict of Interests}

The authors declare no conflict of interests regarding the publication of this paper.

\section{References}

[1] L. D. Petz, "Cold antibody autoimmune hemolytic anemias," Blood Reviews, vol. 22, no. 1, pp. 1-15, 2008.

[2] R. J. Sokol, S. Hewitt, and B. K. Stamps, "Autoimmune haemolysis: an 18-year study of 865 cases referred to a regional transfusion centre," British Medical Journal, vol. 282, no. 6281, pp. 2023-2027, 1981.

[3] S. Berentsen and G. E. Tjønnfjord, "Diagnosis and treatment of cold agglutinin mediated autoimmune hemolytic anemia," Blood Reviews, vol. 26, no. 3, pp. 107-115, 2012.

[4] S. Berentsen, E. Ulvestad, R. Langholm et al., "Primary chronic cold agglutinin disease: a population based clinical study of 86 patients," Haematologica, vol. 91, no. 4, pp. 460-466, 2006.

[5] D. Malesci and G. La Montagna, "Occurrence of cold agglutinin disease in RA patient during etanercept therapy successfully treated with rituximab," Rheumatology, vol. 47, no. 5, pp. 734735, 2008.

[6] E. Cholongitas and D. Ioannidou, "Acrocyanosis due to cold agglutinins in a patient with rheumatoid arthritis," Journal of Clinical Rheumatology, vol. 15, no. 7, p. 375, 2009.

[7] P. Lehmann, W. Hartung, B. Ehrenstein, J. Schölmerich, and M. Fleck, "Rheumatoid arthritis and autoimmune hemolysis:
B-cell depletion for remission induction in a patient with rheumatoid arthritis and cold agglutinin disease," Zeitschrift für Rheumatologie, vol. 69, no. 6, pp. 557-560, 2010.

[8] M. A. Gertz, "Management of cold haemolytic syndrome," British Journal of Haematology, vol. 138, no. 4, pp. 422-429, 2007.

[9] M. A. Gertz, "Cold hemolytic syndrome," Hematology/the Education Program of the American Society of Hematology, vol. 2006, pp. 19-23, 2006.

[10] G. Garratty, L. D. Petz, and J. K. Hoops, “The correlation of cold agglutinin titrations in saline and albumin with haemolytic anaemia," British Journal of Haematology, vol. 35, no. 4, pp. 587$595,1977$.

[11] C. R. Haynes and H. Chaplin Jr., "An enhancing effect of albumin on the determination of cold hemagglutinins," Vox Sanguinis, vol. 20, no. 1, pp. 46-54, 1971.

[12] W. Pollack, H. J. Hager, R. Reckel, D. A. Toren, and H. Singher, "A study of the forces involved in the second stage of hemagglutination," Transfusion, vol. 5, pp. 158-183, 1965.

[13] A. D. Schreiber, B. S. Herskovitz, and M. Goldwein, "Lowtiter cold-hemagglutinin disease. Mechanism of hemolysis and response to corticosteroids," The New England Journal of Medicine, vol. 296, no. 26, pp. 1490-1494, 1977.

[14] C.-S. Chu, S. R. Braun, J. W. Yarbro, and M. R. Hayden, "Corticosteroid treatment of hemolytic anemia associated with Mycoplasma pneumoniae pneumonia," Southern Medical Journal, vol. 83, no. 9, pp. 1106-1108, 1990.

[15] M. Lahav, I. Rosenberg, and A. J. Wysenbeek, "Steroidresponsive idiopathic cold agglutinin disease: a case report," Acta Haematologica, vol. 81, no. 3, pp. 166-168, 1989.

[16] R. Nanan, W. Scheurlen, M. Gerlich, and H.-I. Huppertz, "Severe low-titer cold-hemagglutinin disease responsive to steroid pulse therapy," Annals of Hematology, vol. 71, no. 2, pp. 101-102, 1995.

[17] R. Tsuruta, Y. Kawamura, T. Inoue, S. Kasaoka, D. Sadamitsu, and T. Maekawa, "Corticosteroid therapy for hemolytic anemia 
and respiratory failure due to mycoplasma pneumoniae pneumonia," Internal Medicine, vol. 41, no. 3, pp. 229-232, 2002.

[18] J. D. Cherry, "Anemia and mucocutaneous lesions due to Mycoplasma pneumoniae infections," Clinical Infectious Diseases, vol. 17, no. 1, pp. S47-S51, 1993.

[19] M. Oshima, H. Maeda, K. Morimoto, M. Doi, and M. Kuwabara, "Low-titer cold agglutinin disease with systemic sclerosis," Internal Medicine, vol. 43, no. 2, pp. 139-142, 2004.

[20] T. Kotani, T. Takeuchi, Y. Kawasaki et al., "Successful treatment of cold agglutinin disease with anti-CD20 antibody (rituximab) in a patient with systemic lupus erythematosus," Lupus, vol. 15, no. 10, pp. 683-685, 2006.

[21] M. Kikuchi and T. Inagaki, "A case of primary Sjögren's syndrome associated with low titer cold agglutinin disease," Clinical and Experimental Rheumatology, vol. 20, no. 4, pp. 577578, 2002.

[22] N. Srinivasan, A. Oswal, S. Garg, J. Nahar, A. Gosmonova, and R. Nahar, "Cold agglutinin induced hemolysis in a newly diagnosed systemic lupus erythematosus," The American Journal of the Medical Sciences, vol. 339, no. 3, pp. 270-273, 2010.

[23] K. Nair, K. Pavithran, J. Philip, M. Thomas, and V. Geetha, "Cold haemagglutinin disease in systemic lupus erythematosus," Yonsei Medical Journal, vol. 38, no. 4, pp. 233-235, 1997.

[24] H. Nakamura, K. Kamiya-Matsumoto, A. Kawakami et al., "A case of cold agglutinin disease in the course of treatment for polymyalgia rheumatica," Modern Rheumatology, vol. 19, no. 4, pp. 427-430, 2009. 


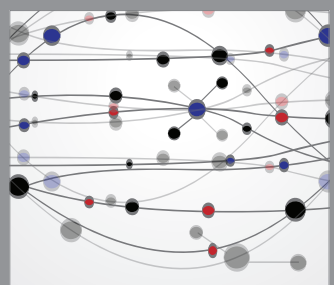

The Scientific World Journal
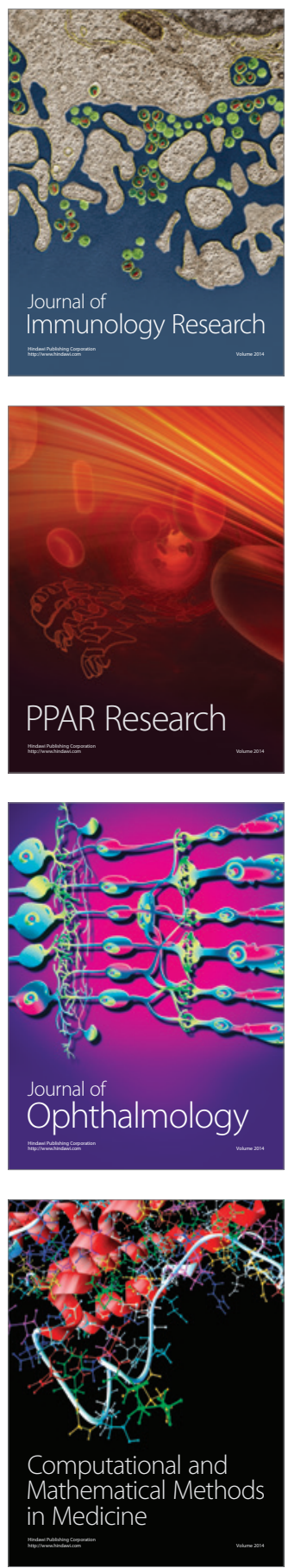

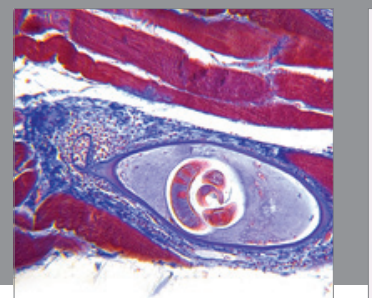

Gastroenterology

Research and Practice
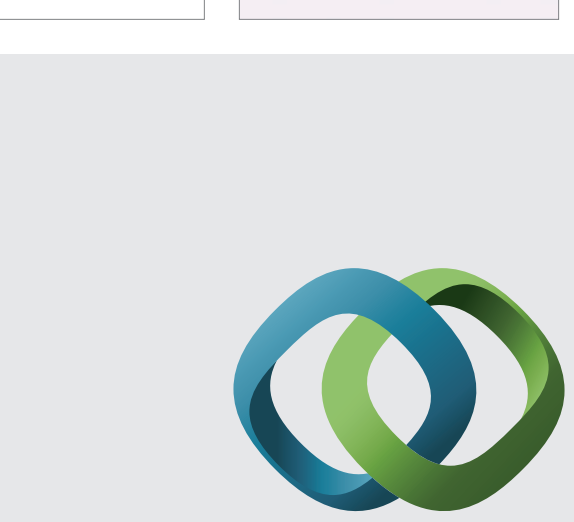

\section{Hindawi}

Submit your manuscripts at

http://www.hindawi.com
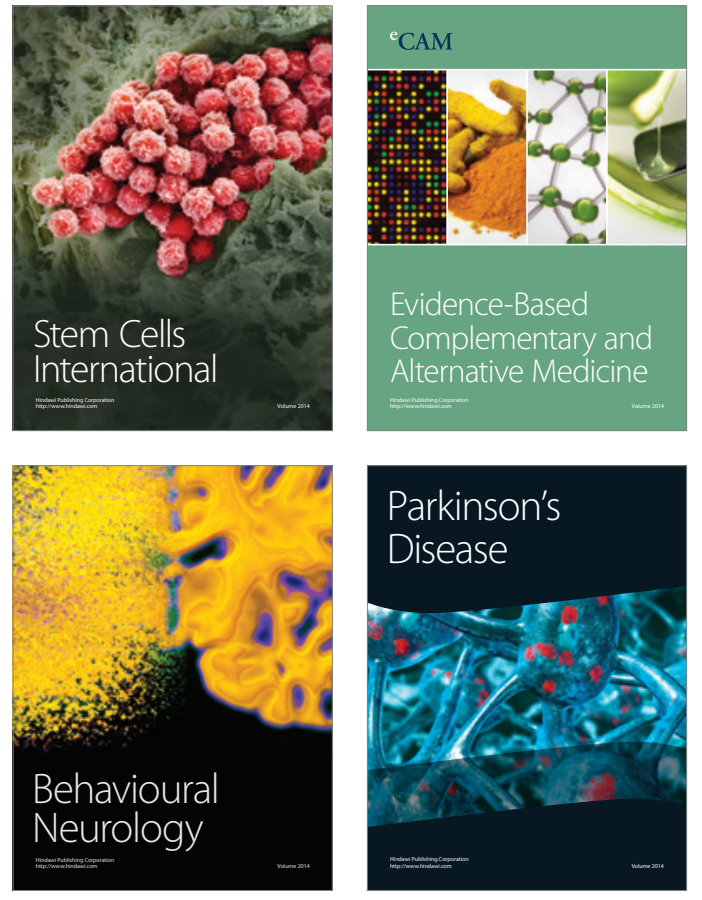


Disease Markers
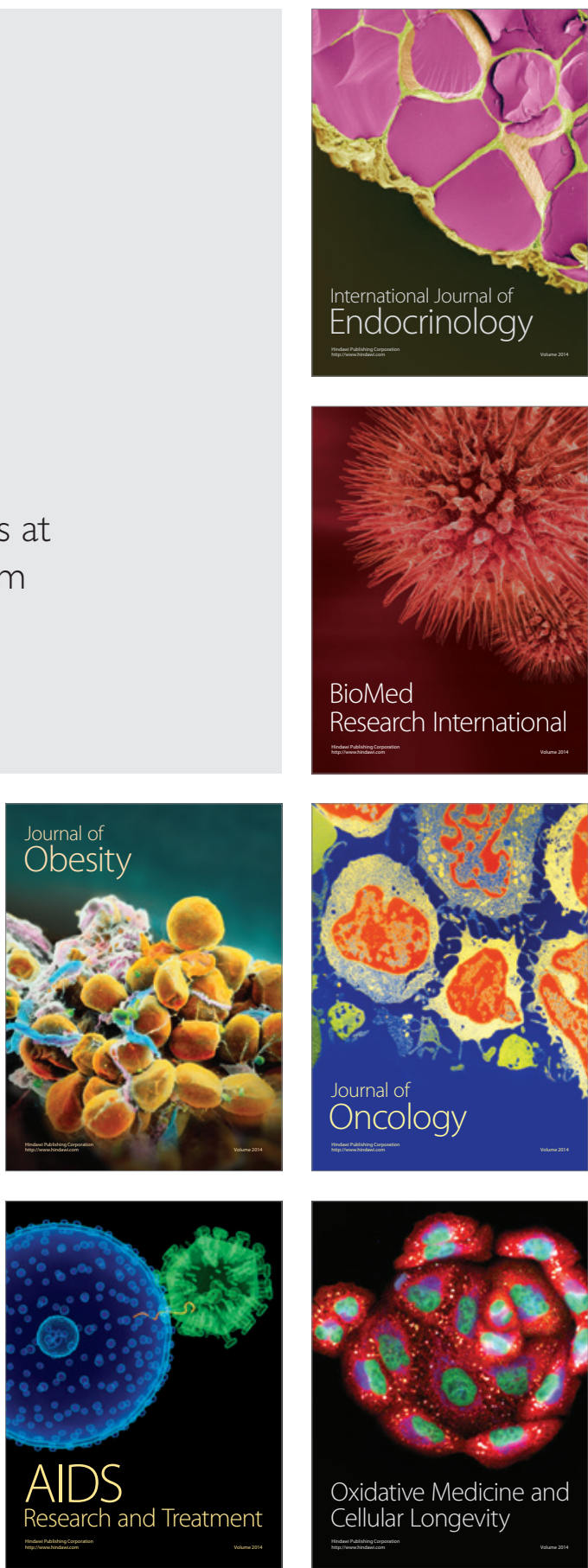